\title{
O caso Binjamin Wilkomirski: a dupla invenção da memória
}

Cláudio Pereira Elmir

Resumo: 0 artigo trata do relato autobiográfico e de sua crítica como documento para a investigação histórica. A través da leitura da recepção do livro F ragmentos, de Binjamin Wilkomirski, cuja origem declarada é dar conhecimento das memórias de uma criança judia nos campos de concentração da A lemanha nazista, pretende-se discutir a legitimidade do uso de narrativas pessoais e o seu frágil e polêmico estatuto como fonte de pesquisa.

Palavras-chave: Relato A utobiográfico. Caso Binjamin Wilkomirski. Shoah. Fraude. Documento

If the literary text is denied the ability to represent reality, so also are all texts, and the distinction traditionally drawn between literature and "document" becomes meaningless, since both participate equally in the uncontrolled play and intertex tuality of languageitself. If we cannot reach "life" through literature, we cannot reach "the past" through document (G abrielle Spiegel, 1990, p. 64).

Q uero começar esta exposição com uma estória recente que fala de presenças antigas na história, mas atualizadas com mais freqüência do que se imagina. Em 1995, Binjamin Wilkomirski publica na A lemanha, pela prestigiosa editora Suhrkamp, um livro

* D outor em H istória pela UFRG S. Professor do Curso de G raduação e do Programa de Pós-G raduação em H istória da UN ISIN OS.E-mail: elmir@ unisinos.br

Anos 90, Porto Alegre, v. 15, n. 28, p. 41-55, dez. 2008 
O caso Binjamin Wilkomirski: a dupla invenção da memória

de memórias intitulado Fragmentos. M emórias de uma infância 1939 1948, cuja versão brasileira foi publicada pela Companhia das Letras em 1998.

0 livro de Wilkomirski trazia à tona, nas palavras de M árcio Seligmann-Silva, um dos mais destacados estudiosos do fenômeno da Shoah no Brasil dos dias de hoje - em resenha publicada no jornal Folha deSão Paulo - "um dos exemplos máximos" da chamada "literatura de testemunho", esta última, segundo ele, "uma das maiores contribuições que o século XX deixará para a rica história dos gêneros literários" (SE LIG M AN N -SILVA, 2005, p.110). 0 entusiasmo do resenhista com a obra recém- lançada se faz perceber, com toda a força que a palavra é capaz de ter, em sua última sentença, quando diz o seguinte: "N um certo sentido, também nós somos agoralevados a escrever como 0 autor: 'E u vi! E u vi!'" (SE LI G M A N N SILVA, 2005, p.112).

$N$ esta declaração, quero ler o desejo de fazer notar a pungência do relato, traduzida pelo perfeito efeito mimético produzido em seu leitor. A representação (no presente) do horror da barbárie (vivida no passado) é capaz de duplicar as sensações pretéritas no leitor cerca de meio século depois da "vivência original", se assim podemos dizer. 0 testemunho de Wilkomirski é, agora, desde a leitura de seu texto, também o testemunho de Seligmann-Silva e, por extensão, o de todos nós.

Não li o livro de Binjamin Wilkomirski, mas, em um ensaio recente de crítica à obra - e especialmente ao autor - , traduzido por René G ertz e publicado na Revista E studos I bero-A mericanos, da PUCRS, temos a reprodução de um trecho do início da narrativa, no qual Wilkomirski narra suas lembranças do assassinato do pai, no gueto, quando aquele tinha três anos de idade. D iz o relato, publicado pela primeira vez em 1995:

A gentes uniformizados, vestindo botas, gritam com ele, 0 levam pela porta. Um grito de medo ecoa pela escadaria. 'A tenção! M ilícia leta!'[sic] Portas batem. 0 homem é levado 
para baixo. E u vou atrás; me grudo no corrimão e vou descendo. [...] Colocaram o homem na parede, ao lado da entrada. A os gritos, os uniformizados embarcam num automóvel estacionado na rua, gesticulam, agitam os porretes e deformam seus rostos numa expressão de ódio. $G$ ritam sempre a mesma coisa, que soa como 'A cabam [sic] com ele! A cabam [sic] com ele!' 0 automóvel se põe em movimento. Acelera em direção à parede, em direção a nós. 0 homem continua imóvel, encostado na parede, perto de mim. Estou sentado no chão, entre a porta e a parede, os olhos voltados para ele. Ele baixa os olhos para mim e abre um sorriso. Mas, de repente, seu rosto se desfigura, ele o vira para o lado, levanta a cabeça, abre a boca, como se quisesse soltar um grito. Lá de baixo, contra a claridade do céu só consigo enxergar ainda os contornos de seu queixo e o chapéu, que resvala para trás. $\mathrm{N}$ enhum grito ecoa de sua boca, mas um jato preto sai de sua garganta, quando 0 automóvel 0 imprensa contra a parede (apud HEUER, 2006, p. 39).

Creio que a leitura (audição) dessa narração seja suficiente para compreendermos por que, por seu meio, temos acesso à visão da cena narrada. A "clareza fotográfica" (cf. HEUER, 2006, p. 39) que ela encerra diz, afinal, o motivo de os eventos se oferecerem (novamente, numa (im) possível replicação da experiência) a nós. É como se, repentinamente, a dissimetria cronológica se desfizesse, e se transmutasse numa prodigiosa sincronicidade. No limite, não estamos com Wilkomirski na ocasião do assassinato de seu pai, somos o próprio filho quando o trauma nele se instala.

Wolfgang $\mathrm{H}$ euer e M árcio Seligmann-Silva, entre outros, contam-nos a trajetória de sucesso do livro de Wilkomirski, à qual o primeiro autor referiu-se em termos de "uma procura ansiosa por histórias desse tipo" (HEUER, 2006, p.42). E ssa afirmação pode levar-nos à perigosa conclusão de que histórias são escritas, na forma como o são, tendo em vista uma suposta expectativa de recepção favorável a elas. Existe uma predisposição social para o consumo de produtos desta natureza. ${ }^{1}$ A causalidade tosca fica um pouco 
menos frágil - mas não completamente - quando lembramos que o livro foi lançado no âmbito das comemorações dos 50 anos da derrocada do nazismo e do fim da Segunda Guerra M undial, com a vitória dos aliados. D e certa maneira, é preciso considerar esta variável quando pensamos no "ambiente receptivo" encontrado por F ragmentos, elemento não destacado na análise feita por H euer. Q uem se desse ao trabalho, se ainda não houve quem o fez, de inventariar as produções realizadas, referentes a estas temáticas, provenientes dos mais diferentes lugares da cultura, apenas para 0 ano de 1995, poderia, eventualmente, confirmar esta minha intuição: a carga simbólica conferida à efeméride potencializou e multiplicou 0 efeito de recepção do relato. Creio que haja indícios suficientes para não excluir esta hipótese.

Wilkomirski, segundo seu relato, viveu, durante o nazismo, nos campos de M ajdanek, A uschwitz e Birkenau. Passou a morar, posteriormente, em um abrigo para crianças na Suíça, e seu nome foi trocado, não se sabe por que circunstâncias, para Bruno G rosjean e, depois de adotado, para Bruno D össekker. E studa H istória e aprende a construir instrumentos musicais, trabal hando como músico. Já adulto, é incentivado a escrever sua história (cf. HEUER, 2006, p.40).

D e maneira geral, o livro obteve uma recepção francamente favorável e elogiosa, tanto na imprensa quanto no meio acadêmico. Foi traduzido, pelo menos, para doze línguas, sendo publicado por editoras renomadas. 0 livro recebeu vários prêmios, em diferentes países. Com base nele, foram produzidos três filmes e uma peça de teatro. A lém de ser requisitado para palestras nas principais universidades norte-americanas e européias, "Wilkomirski deu um longo depoimento sobre a sua história (seis fitas de vídeo) para o H olocaust Memorial M useum deWashington. Também Survivors of the Shoah V isual H istory Foundation, instituição financiada por Spielberg e que se encarrega de construir um fantástico arquivo de vídeos com entrevistas de sobreviventes da Shoah, entrevistou o nosso autor" (SE LIG M AN N -SILVA, 2005, p. 113).' Com a ajuda de um psicoterapeuta judeu seu amigo, "(...) apresentou em diversos congressos 
científicos um método terapêutico próprio. A través da combinação entre Psicoterapia e Ciência H istórica, esse método se propõe a despertar a memória da primeira infância, e com isso ajudar a todas aquelas pessoas que têm dúvidas sobre suas origens a esclarecer sua identidade" (HEUER, 2006, p. 41).

Foram poucas as manifestações de desconfiança em relação à veracidade do relato autobiográfico, à ocasião mesma de seu lançamento. Contudo, três anos passados desdea publicação original, quando recém saía a edição brasileira pela Companhia das Letras, veio à tona o desmascaramento do autor. Compreendeu-se, finalmente, por que "nunca um testemunho das atrocidades nazistas tinha atingido 0 detalhamento que essa obra contém" (SE LIG M AN N -SI LVA, 2005, p.113). 0 "excesso de realidade" não era mais apenas, como muito se acreditou, um impeditivo para a verbalização (e exposição) de uma memória traumática. ${ }^{3}$ E ra, agora, fruto de uma imaginação solerte, cujo fim, ao que tudo indica, residia no deliberado interesse de produzir o engano alheio, quem sabe por uma espécie de "comunhão espúria" entre o autor e o leitor ou, mais exatamente, entre 0 texto e o leitor. Afinal, é de um texto escrito que estamos falando, e das reações de crença e suspeita que ele foi capaz de suscitar em diferentes momentos, num curto lapso de tempo.

Talvez as coisas pudessem se arranjar na constatação da falsificação do relato. Mas temos aprendido, ao longo dos anos, que os caminhos da fraude são um pouco mais sinuosos (sofisticados mesmo), e as resoluções, mais demoradas. 0 escritor judeu $D$ aniel G anzfried foi o responsável por, em muito pouco tempo, fazer uma investigação sobre a identidade do autor e concluir pela farsa, publicando este resultado em um jornal suíço em agosto de 1998 (cf. HEUER, 2006, p. 41). D e fato, Wilkomirski era um personagem inventado por Bruno D össekker. Se o editor da Suhrkamp se fez de morto e deixou esgotarem as edições - a de capa dura e a de bolso -, mais surpreendente é 0 relato, feito por Wolfgang $\mathrm{H}$ euer, da reação do editor norte-americano do livro. Tal relato diz o seguinte: 
O caso Binjamin Wilkomirski: a dupla invenção da memória

Seu editor nos E stados U nidos, Arthur Samuelson, daSchocken Books, declarou que a diferença entre fads and fiction não interessava. Segundo ele, F ragments 'is a pretty cool book... It's only a fraud if you call it non-fiction. I would then reissue it, in the fiction category. Maybe it's not all true - then he's a better writer!' N ão é 0 autor que falsifica, mas sim o leitor, quando afirma que no caso de Fragmentos se trata de um relato factual (HEUER, 2006, p. 42).

0 problema agora, então, não é mais a autenticidade do testemunho, mas a classificação do texto. A ficha catalográfica é que está errada. 0 bibliotecário é quenão soubefazer o correto enquadramento da obra. 0 leitor é um ingênuo, decodificando literalmente o que pedia outra chave de acesso. Jogou o jogo com regras impróprias e, agora, sente-se, injustamente, lesado. I sso mais está parecendo uma "conversa de doido", para aqui lembrar uma frase da antológica personagem de A ntônio Biá (José D umont) no belo filme "N arradores de Javé" (CAFFÉ, 2003 ), 0 autodenominado "escriturário e alcoólatra" de sua comunidade, que se afigurava ter mais discernimento que seus (nem tão) sóbrios conterrâneos.

Vamos lembrar que, para além das intenções contidas em "fichas catalográficas", existem as intenções dos leitores e aquelas que o autor expressa tanto no texto de seu relato, quanto em inúmeras circunstâncias fora do próprio livro. N enhum historiador pode se eximir, na tarefa de escrutinar o texto (documento), da perseguição das múltiplas intertextualidades que ele é capaz de fazer acessar. 0 diálogo intertextual pode ser um eficaz mecanismo de romper com a ordem (aparentemente perfeita) vigente no interior do texto. É bastante conhecida a idéia de que a coerência interna é um critério frágil para o estabelecimento da evidência no trabalho do historiador. A reiteração do "mesmo" é apenas aquilo que ela pode ser, a saber, uma operação tautológica incapaz de fazer ver as fissuras do relato. Tratando-se aqui de um relato autobiográfico, a vontade de imprimir ordem no testemunho, pelo autor, pode prejudicar 0 
valor epistemológico de uma crítica, quando esta se afigura complacente com este propósito.

Se a moderna crítica historiográfica corretamente nos ensina a prestar atenção no texto - superando a simples enumeração de repertórios aparentemente assépticos e desprovidos de consistência teórica, que vigorou por um determinado tempo, e, de outro lado, transpondo a crítica ideológica dos documentos, que, a rigor, prescindia de conhecimento textual para a sua realização (v. GUIMARÃES, 2005) - , no caso específico de um relato autobiográfico, sucumbir à tentação de analisar a narrativa como se ela se encerrasse nela mesma pode se tornar, metodologicamente, um caminho seguro para o precipício. N este sentido, alerta Jeremy Popkin: "0 caso Wilkomirski nos chama a atenção que autobiografias, não importa quão persuasivas, não são auto-validáveis (PO PK IN , 2002, p. 24). Márcio Seligmann-Silva, na "Contra-resenha" produzida para 0 mesmo jornal Folha de São Paulo, oito meses após a primeira - aqui já mencionada - , faz um mea-culpa de sua avaliação inicial. D iz ele: “(...) percebemos em que medida nós nos abrimos de modo sentimental, e não suficientemente racional, para essa literatura. D e agora em diante, os estudiosos da Shoah serão mais cautelosos" (SE LIG MAN N -SILVA, 2005, p.114).

E ssa necessidade de cautela émencionada por Tony K ushner, ao reivindicar para os estudiosos, ao mesmo tempo, o exame da dinâmica interna do testemunho, capaz de revelar suas mitologias e contradições, que, para ele, são "a natureza real de qualquer história de vida" (K USH N ER, 2006, p. 283) e, por outro lado, "a necessidade essencial de contextualizar tais testemunhos no tempo e no espaço e não considerá-los como sui generis" (K USH NER, 2006, p. 285).

$\mathrm{N}$ o caso em particular que estamos aqui abordando, a condição de ser, para além de uma autobiografia - aliás, em termos, já que se restringe a narrar a trajetória de vida de uma criança, entre os três e os sete anos de idade - , um texto que se ajusta àquilo que se convencionou denominar de "literatura de testemunho" parece complicar um pouco mais as coisas. D aniel Levy e $N$ atan Sznaider chamam 
O caso Binjamin Wilkomirski: a dupla invenção da memória

justamente a atenção para os riscos de se lidar com uma noção trans-histórica de "trauma" no estudo do Holocausto. Acredito que, ao se constituírem estes estudos, em campo nitidamente transdisciplinar, o aparato teórico-conceitual com o qual os pesquisadores precisam operar em suas investigações torna-se necessariamente múltiplo e mais refinado. A este respeito, os autores afirmam: "A maioria dos historiadores e dos cientistas sociais não está treinada na linguagem psicanalítica a fim de analisar o trabalho com o trauma em termos pessoais. Reciprocamente, a maioria dos psicanalistas não está treinada para transferir sua terminologia do trauma para examinar a história e a sociedade" (LEVY e SZN AIDER, 2006, p. 7). ${ }^{4}$

Algumas dessas insuficiências se revelam no desdobramento que teve a descoberta da fraude construída por Wilkomirski/ D össekker. Alguns textos que tratam do caso comentam a possibilidade de o autor ser um "mentiroso patológico". Dizem Levy e Sznaider: "(...) não éinteiramente implausível queW ilkomirski realmente acreditasse na sua própria fabricação" (LEVY e SZN AIDER, 2006, p. 4). O ra, qual o corolário possível desta hipótese, caso pudéssemos confirmá-la ou mesmo antes de testar a validade da afirmação? Q ue implicações ela acarreta na particular relação que o historiador, por exemplo, estabelece com este texto como fonte de pesquisa? Parece pacífico que esta alternativa não encontra sua resolução no campo da história. $\mathrm{O}$ u seja, os historiadores não têm instrumentos, nem, sequer, competência técnica para solucionar esta questão. A prerrogativa da atribuição do rótulo de mitômano pertence, é bem sabido, a outro campo disciplinar, ao qual, em decorrência de nossa formação, temos o ingresso interditado, afinal, não podemos nos instituir em terapeutas de D össekker.

A Wolfgang H euer, parecem não interessar tanto essas ressalvas por mim levantadas, quando afirma: "D össekker já apresentava ataques epiléticos na escola, e eles se manifestavam através de representações muito bem executadas" (HEUER, 2006, p. 45). E u pergunto: o que um cientista político - como é o caso de H euer - e um historiador podem fazer com esta "informação"? O utra notícia, 
trazida também posteriormente à descoberta do caso, acerca da intimidade do autor com a história do H olocausto, permite o estabelecimento de mais algumas ilações. Ela diz o seguinte: "(...) ele estudou H istória em G enebra. A sua paixão pela história é comprovada também pelo enorme arquivo que ele organizou sobre o tema: o que deve ter servido de ajuda para a compilação da sua 'outra' vida, a fictícia, de um 'sobrevivente' de A uschwitz" (SE LI G M AN N SILVA, 2005, p. 115).

E stamos aqui na inusitada situação pela qual se coloca o "arquivo" a serviço da "invenção", em um texto autobiográfico. N esse caso, a um historiador muito interessaria perscrutar os escaninhos da casa de Dössekker, na sua biblioteca particular. E, ainda, mexer nas anotações dispostas sobre a sua mesa, ou guardadas nas suas gavetas, ou inscritas nos livros que repousam em suas estantes, ou registradas na "memória" de seu computador pessoal. A grande obsessão do historiador de se encontrar com o "acontecido" se realizaria, paradoxalmente, na descoberta das "fontes" que informam a mentira habilmente engendrada. Q uem sabe com essa operação nos fosse dado a saber uma série de marcas de erudição que ninguém gostaria de encontrar em uma narrativa pessoal. Será que o lugar de origem da "lembrança" são os livros e os documentos da barbárie coletiva, da qual o menino Bruno Dössekker esteve convenientemente preservado? 0 "gesto de selecionar" (DE CERTEAU, 1976, p.30) que instaura o trabalho do historiador talvez pudesse ser divisado - de maneira deslocada - nesta busca imaginária à casa do autor.

Críticos de fontes escritas costumam chamar a atenção, em suas prescrições metodológicas, para a precaução que devemos tomar quando alguém "(...) descobre uma fonte inesperadamente e em circunstâncias obscuras, e também se só se conhece uma cópia e o original não foi visto nunca por ninguém" (T O PO LSK I, 1992, p.149). Há ainda que se considerar os casos em que sequer as cópias são de domínio público. 
No caso em específico do livro Fragmentos não é exatamente esse o problema. Os A rquivos são lugares (instituições) que, em parte e preliminarmente, sancionam os documentos mantidos sob sua guarda. M as aqui, no relato autobiográfico, uma visão singela diria que o documento, o "fundo" e o "A rquivo" residem, todos, no pensamento e, depois, na palavra do autor. é bem possível que as coisas sejam mais complexas que 0 arranjo ligeiro que eu fiz destes termos. E o caso Binjamin Wilkomirski está aí para nos dizer isso.

Verena A lberti, em um instigante artigo publicado na revista E studos H istóricos em 1991, no qual discute "a questão do sujeito na narrativa", especialmente no caso da construção autobiográfica, desenvolve, demoradamente, o labirinto conceitual que circunda esta questão e que, evidentemente, não temos como recuperar satisfatoriamente nesta apresentação. E la lembra o conceito de "pacto autobiográfico" (LEJEUNE, 1975), pelo qual "(...) a identidade entre autor, narrador e personagem é condição sine qua non de uma autobiografia" (ALBERTI, 1991). E u diria que o pacto, no caso da obra aqui analisada, foi rompido quando o personagem fictício da trama, ele próprio, assinou a obra. A pós a descoberta da fraude, Dössekker, em uma entrevista para um jornal, providencialmente, negou esta identidade, ao dizer: "O s leitores sempre estiveram livres para aceitar meu livro como literatura ou como documento pessoal" (apud SE LIG MAN N -SILVA, 2005, p. 116). N este momento, o pacto pressuposto se desfaz e 0 autor sinaliza para a cômoda opção de reivindicar os benefícios do "pacto romanesco". $\mathrm{N}$ este caso, o fingimento estaria legitimado e, com isso, desfazem-se, também, quaisquer embaraços éticos.

0 ra, 0 que significa, a partir deste momento, pensar em $\mathrm{Frag-}$ mentos como obra de ficção, e não mais como trabalho de memória, no sentido que este pode assumir em um texto autobiográfico? Tomar como ponto de partida da leitura a inclusão do livro no âmbito da ficção o torna "imediatamente má literatura de ficção" (SE LIG M AN N -SILVA, 2005, p. 116). A o mesmo tempo, como 
combinar esse juízo com uma outra avaliação feita, pelo mesmo autor e no mesmo texto, e que diz o seguinte: "Se a sua obra continua a ter ou não um valor estético, mesmo após a descoberta da farsa, é outra questão que cada um deve decidir individualmente" (SELIG MAN N-SILVA, 2005, p. 116)?

E $\mathrm{m}$ uma perspectiva de análise distinta, quanto à avaliação da qualidade da narrativa, Valeria de M arco menciona a oscilação valorativa da obra, feita pelos críticos, consoante a circunstância. A o fazer a defesa da manutenção de uma distinção entre as dimensões ética e estética do texto, ela diz:

Em um primeiro momento, ela foi considerada como texto de excelente qualidade e, quando se comprovou que seu autor jamais havia estado em um campo de concentração, passou a ser péssima, pois era produto de uma "mentira". A fraude da identidade do autor é uma questão grave que pode ser julgada em muitas instâncias sociais, mas ela não pode ser determinante para a análise e interpretação do texto (DE MARCO, 2004, p. 60).

Para alimentar a controvérsia, há quem diga que o livro de Wilkomirski "(...) podeser um bom romance. E le pode ser lido separadamente de uma consideração acerca da pessoa que o escreveu. $F$ ragmentos é de fato melhor do que muitos outros romances sobre 0 H olocausto" (GERAS, 2002, p. 122). Prejudica-se, segundo estas duas últimas leituras, a discussão sobre a existência de um problema ético envolvendo a obra e 0 autor, o que não compromete 0 valor estético da obra, posição da qual Seligmann-Silva parece discordar. 0 que fazer, neste caso, com " (...) a fronteira convencional, institucional, entre um trabalho oferecido como autobiografia [memoir] e um trabalho oferecido como romance [novel]?" (SU LE I M A N, 2000, p. 545-6). Tal fronteira, de fato, existe e Susan Suleiman entende que o problema com este livro é que ele não reconhece, não admite a sua própria ficcionalidade desde o seu surgimento. D evemos considerar que sua admissão se dá tardiamente, em um contexto 
O caso Binjamin Wilkomirski: a dupla invenção da memória

de denúncia da obra, funcionando a mesma como uma espécie de salvo-conduto erigido pelo autor e por alguns de seus editores. A mesma autora se pergunta: "O nde a literatura termina (ou começa) e a psicopatologia começa (ou termina)? (...) A quem a memória do Holocausto pertence?" (SULEIMAN, 2000, p. 554). Essa também é uma questão polêmica e irresoluta, como veremos a seguir.

Leila D anziger, ao trabalhar com a arte contemporânea, tematicamente focada no H olocausto, lembra o Caso Binjamin Wilkomirski e acrescenta, nesta nossa discussão, mais um elemento que aponta a dificuldade de se produzir uma avaliação judiciosa para este imbrógio. Segundo uma investigação feita por Stephan M ächler, por ela mencionada, a mudança de identidade estaria associada a uma necessidade de se ver aceito pela comunidade, o que seria muito mais fácil de acontecer reivindicando um repertório desofrimento deamplo conhecimento social:

\begin{abstract}
Wilkomirski/ G rosjean transporta - literalmente - suas memórias autênticas do sofrimento vivido quando criança na Suíça para a topografia dos campos e da errância do pós-guerra. Com Wilkomirski vem à tona, de modo grotesco, 0 fato de que a memória individual se alimenta da memória coletiva (DAN ZIGER, 2003, p. 73).
\end{abstract}

As chances de uma aprovação sem reservas, no caso dessa narrativa, são maiores do que numa história de uma criança infeliz, ilegítima, proletária e adotiva (M ÄCH LER apud DANZIGER, 2003, p. 73).

$\mathrm{N}$ ão sei ao certo o que fundamenta este tipo de conclusão. M as, novamente, ela se parece com uma justificativa moral para a impostura de G rosjean/ D össekker. E stamos diante de uma "disposição para iludir e auto-iludir-se?" Coloca-se aqui um certo "fascínio pelo trauma?", "uma inclinação para a autovitimização"? (HE UE R, 2006, p. 44). D anzig e H euer lembram que um dos fenômenos associados à memória do Holocausto é "essa luta pela auto-inclusão entre as 
vítimas [que] também atinge a 'segunda geração' dos sobreviventes" (HEUER, 2006, p. 44). 0 que significa esta "herança compartiIhada" (v. DANZIGER, 2003, p.72)? 0 que pode haver de próprio na contração da dor alheia? Como lidar epistemologicamente, no campo disciplinar da história, com esse fenômeno?

Para finalizar esta estória, creio que faz parte da responsabilidade política - para além das questões da natureza da fonte, aqui muito tenuemente abordadas - dimensionar o impacto social que o embuste erigido por D össekker acarreta em termos do reforço a posições neonazistas ("revisionistas") na atualidade, especialmente na E uropa (NESTROVSK I, 2000, p. 201). A final de contas, não vamos nos iludir. O s historiadores não são os leitores-modelo dessa pseudo-memória. Se memórias autobiográficas são fontes de pesquisa extremamente frágeis em si mesmas, tentar sair, momentaneamente, do "bosque" (narrativa) para ver o que lá fora há, pode ser um antídoto relativamente seguro para não ser tragado pelo lobo mau. Se, como diz o adágio popular, "o papel aceita tudo", impõese ao trabalho historiográfico responder a esta potencial "disenteria" de tinta - para, de novo, recordar Antônio Biá - , com a melhor tradição crítica que estiver ao nosso dispor. Sem esquecer, contudo, a lição básica de que "nós não podemos ver o testemunho como uma janela para o passado", ao mesmo tempo em que nunca é demais lembrar: "no coração de qualquer memória está o esquecimento" (BERN ARD -D O N ALS, 2001, p. 1302 e 1313).

TheB injamin Wilkomirski case: the double invention of memory Abstract: This article deals with the autobiographical report and its criticism as a document for historical investigation. Through the reading of the reception of F ragments, by Binjamin W ilkomirski, whose alleged origin is to tell the memories of a ewish child in $\mathrm{N}$ azi $\mathrm{G}$ ermany concentration camps, we intend to discuss the legitimacy of the use of personal narratives and their fragile and polemic status as aresearch source.

Keywords: A utobiographical report. Binjamin Wilkomirski case. Shoah. Fraud. Document 
O caso Binjamin Wilkomirski: a dupla invenção da memória

\section{N otas}

${ }^{1}$ Talvez seja exagero dizer que "Wilkomirski foi, sem dúvida, tão bem sucedido por causa da relação simbiótica queestabeleceu com seu público. E leseentregara deforma total ao papel que se auto-atribuíra, e, da mesma forma, o público estava disposto a entregar-se de forma total ao seu mundo eà sua realidade" (HEUE R, 2006, p. 47). 2 "Sua entrevista, concedida à Fundação Survivors of theShoah, em 20/ 03/ 1997, a que tive oportunidade de assistir, éuma encenação de péssima catego ria, marcada por uma exagerada retórica de convencimento, bem diferente de seu livro extremamente sutil" (SE LIG M AN N -SI LVA, 2005, p. 116).

${ }^{3} \mathrm{U}$ m dos paradoxos levantados nas reflexões sobre estefenômeno diz o seguinte: "Como narrar o horror dos campos de concentração, se os que o viveram inteiramentenão sobreviveram paracontar? O squesobreviveram enfrentam o dilaceramento entre a culpa por ter sobrevivido e o imperativo ético da necessidade de narrar sem trair a verdade" (DE M ARCO, 2004, p. 55). Ver, a esterespeito, a título de exemplo, al guns dos depoimentos que constam no vídeo "Sobreviventes do H olocausto", produzido por Steven Spielberg (E UA; 1995).

${ }^{4} \mathrm{~A}$ conclusão do artigo revela, com nitidez, a concepção de história que está informando sua análise, a saber: "T heH olocaust and other man made catastrophes were real and it is this reality which defines political responsability in our age. This is true for social theorists as well. I f we think trauma to be a useful concept, we should al ways keep the human and historical dimension in mind whilekeeping its structural elements at bay. If not we might as well do without it" (LEVY eSZNAIDER, 2006 , p. 8).

\section{Referências}

ALBE RTI, Verena. Literatura e autobiografia: a questão do sujeito na narrativa. E studos H istóricos, v. 4, n.7, p. 66-81, 1991.

BE RN ARD-D O N ALS, M ichael. Beyond the question of authenticity: witness and testimony in the F ragments controversy. PM L A (M odern Language A ssociation), v. 116, n. 5, p. 1302-1315, 2001.

CAFFÉ, E liane [vídeo]. 0 s narradores de Javé. BR; 2003 (100’).

DAN ZIGER, Leila. Tarefa infinita: percursos entre história, memória e esquecimento. I potesi, v. 7, n. 2, p. 61-77, julho-dezembro 2003.

DE CERTEAU, M ichel. A operação histórica. In: LE G O FF, Jacques e N O RA, Pierre (O rg). H istória: novos problemas. Rio de Janeiro: Francisco Alves, 1976, p. 17-48. 
DE MARCO, Valeria. Literatura de testemunho eviolência deE stado. L ua N ova, $n$. 62, p. 45-68, 2004.

G ERAS, N orman. The true Wilkomirski. Res Publica n. 8, p. 111-122, 2002.

GUIM ARÃES, M anoel L uiz Salgado. H istoriografia ecultura histórica: notas para um debate. A gora, Santa Cruz do Sul, v. 11, n. 1, p. 31-47, jan./ jun. 2005.

HE UER, Wolfgang. A síndrome de Wilkomirski: história falsificada. E studos I beroA mericanos, PU CRS, E dição E special, n. 2, p. 35-47, 2006.

K USH N E R, Tony. H olocaust testimony, ethics and the problem of representation. Poetics Today v. 27, n. 2), p. 275-295, (summer 2006).

LEVY, D aniel eSZN AIDER, N atan. Thepolitics of commemoration: the holocaust, memory and trauma. In: DELAN TY, G (E d). $\mathrm{H}$ andbook of the Contemporary $E$ uropean Social Theory. N ew York, Routledge, 2006, p. 289-297.

NESTROVSK I, A rthur. Vozes de crianças. In: NESTROVSKI, Arthur e SE LI G M AN N -SI L VA, M árcio (org.). C atástrofe erepresentação. São Paulo: E scuta, 2000, p. 185-205.

POPK IN, Jeremy D. First-Person narrative and the memory of the holocaust. I deas, v. 9, n. 1, p. 16-25, 2002.

SE LI G MAN N -SILVA, M árcio. Literatura de testemunho: os limites entre a construção e a ficção. In: 0 local da diferença. Ensaios sobrememória, arte, literatura e tradução. São Paulo: 34, 2005, p. 105-118.

SPIE GE L, G abrielle. H istory, historicism, and the social logic of the text in the M iddle A ges. Speculum, v. 65, n.1, p. 59-86, jan. 1990.

SPIE LBE RG, Steven [vídeo]. Sobreviventes do H olocausto. EUA; 1995 (70').

SU LE IM AN, Susan Rubin. Problems of memory and factuality in recent holocaust memoirs: Wilkomirski/ Wiesel. Poetics T oday, v. 21, n.3, p. 543-559, 2000.

TO PO LSK I, Jérzy. La autenticidad de las fuentes y la fiabilidad de los informantes. In: M etodologia de la historia. 3. ed. M adrid: Cátedra, 1992, p. 333-349.

Recebido em 05/ 12/2008

A provado em 23/ 12/ 2008 